\title{
BIOMOLECULAR SKILL ENHANCEMENT PROGRAM FOR LABORATORY STAFFERS OF POLITANI KUPANG IN SUPPORTING AGRICULTURAL- RELATED LAB PRACTICES AND RESEARCHES
}

\author{
Stormy Vertygo*, Fanmarinat S. Inabuy** \\ *State Agricultural Polytechnic of Kupang \\ ** Udayana University \\ e-mail: svertygo91@gmail.com
}

\begin{abstract}
As one of the prominent vocational institution in East Nusa Tenggara (NTT), State Agricultural Polytechnic of Kupang (Politani Kupang) strives to create graduates not only with field skills but also sufficient skills in the laboratory. In fact, most of the laboratories in the institution are very well equipped with high and vast technologies of the latest innovations, especially for molecularlevel analysis. However, much is still unknown from the lab staffers on the procedures to operate it. Unfortunately, this would in turn hinder the assistance in academic activities such as lab practices, sample analysis and researches related to Agricultural field. To optimise these facilities and being of any assistance, Politani Kupang in coordination with Forum Academia NTT (FAN) and Institute of Resource Governance and Social Change (IRGSC) Kupang initiate the program to enhance the skills of Politani Kupang lab staffers in Biomolecular field. This training was conducted from $15^{\text {th }}$ to $20^{\text {th }}$ of June 2020 in the Laboratory of Agricultural Biotechnology under the major of Crop \& Horticulture Plants. By the end of the program, it could be concluded that the lab staffers have now become more familiar with the basic procedures to operate/run lab apparatuses/methods such as: RNA isolation, Electrophoresis, UV Gel-doc, PCR and qPCR machines.
\end{abstract}

\section{Keywords : Agricultural-related, Biomolecular skills, Enhancement, Lab staffers, Politani Kupang}




\section{INTRODUCTION}

Vocational education champions to change one's comportment in order to enhance his/her quality of life through work and values either solely or supplemented with academic education. (Importance of Vocational Education | Independent, n.d.). In contrast with vocational education, an academic education generally offered by Universities tends to have learning as its primary goal which mainly explores around the theoretical and hypothetical aspects of a certain subject or knowledge, but however, is not necessarily practical, realistic or directly useful (Education, 2013). By providing and developing technical knowledge as well as practical skills, a vocational institution missioned to create graduates with skills that are specific to a certain trade or job role that could in turn increase their employment prospects, including through self-employment or entrepreneurship (Bangham, 2018).

In East Nusa Tenggara, Agricultural Polytechnic of Kupang (Politani Kupang) serves as one of the leading institution in providing vocational education for its students. Each student depending on his/her major and study program will be equipped with the specific skills required for developing their future career where suitable. In order to assist this goal, Politani Kupang has had facilities and infrastructures which go hand in hand with the curriculum constructed. Supplementary source of skill development also comes from certain activities such as Field Employment Practise or 'Praktek Kerja Lapangan' where the students are located in certain businesses for a short period of time to learn, practise and polish their skills first-hand. Another example is: Independent Business Project or 'Proyek Usaha Mandiri' usually preceding the former mentioned above where the students will be given a certain amount of financial capital that he/she will have to be able to organize it for an assigned business project and create profit out of it. Last but certainly not least, laboratories have also been provided with equipment or apparatuses of the latest innovations. Unfortunately, for some of the facilities, especially those related to molecular-based analysis, most of it hasn't been known by the lab staffers yet on how to operate it and the purpose of its operation. Consequently, this would in turn hinder the Teaching-Learning Process especially during Lab practices as well as researches and sample analysis related to the agricultural field. 
In response to such issue, Politani Kupang initiated the idea for an enhancement training program in the field of molecular-based analysis for its lab staffers. This was also made possible by coordination with Forum Academia NTT (FAN) and Institute of Resource Governance and Social Change (IRGSC) Kupang which provided the human resources capable of operating those facilities. By undergoing such training, the lab staffers are expected to be able to operate those molecular-related apparatuses and optimize its use in assisting the lecturers in providing technical knowledge and practical skills for their pupils.

\section{METHOD}

The Biomolecular skill enhancement program started from $15^{\text {th }}$ to $20^{\text {th }}$ of June 2020 at the Laboratory of Agricultural Biotechnology, Politani Kupang. Laboratory staffers involved in this training ranged from the study program of Feed Manufacture Technology, Animal Health, and Agriculture Biotechnology to Plant Conservation. The staffers were presented with different biomolecular-based topic each day, with the first session started with a brief look at the theoretical aspects of the topic, what kind of samples suitable for a certain tool and/or method and then followed with a second session of practical aspects in operating or conducting the tools and/or methods under safety protocols.

For RNA extraction, equipments used were: micropipette and its tips, cutter, centrifuge, spin column, vortex, collection tube, incubator, freezer, mortar and its pestle, while the materials used were: Lactobacillus spp. culture, RNA extraction kit, Alcohol 70\%, DEPC-treated water, buffers (RLT, RTS, RW1 RPE), EtOH, and $\beta$-merkaptoetanol.

For Polymerase Chain Reaction (PCR) and qPCR, equipments used were: PCR machine, qPCR machine, micropipette and its tips, centrifuge and 96 well microplate, incubator, while the materials used were: cDNA synthesis kit, bacterial RNA template, PCR-grade water, ice, Tris$\mathrm{HCl}$, EDTA, Amplification buffer, dNTP MIX, Forward and Reverse Primers, thermostable DNA taq polymerase.For Electrophoresis, equipments used were: Eppendorf tubes, micropipette 
and its tips, centrifuge hotplate, electrophoresis device, power supply, while the materials used were: agarose gel, buffer TAE 1X, loading dye, Red Gel.

\section{RESULTS AND DISCUSSION}

\section{RNA Extraction}

RNA extraction was the first topic to be discussed and practised inside the lab. The source of RNA used was from a bacteria species (Lactobacillus sp.). During this session, the staffers really got to know the standard procedures on how to remove a piece of RNA from a certain sample given. They also should be able to take a small precise amount of buffer solution during a serial of treatments before the bacterial RNA could be extracted. Therefore, their skills and abilities to be able to use the micropipette were also trained and assessed during this session.

The RNA extraction procedure was conducted as follows:

1. Bacterial culture was centrifuge at $5000 \mathrm{x} \mathrm{g}$ speed for 5 minutes at $4^{\circ} \mathrm{C}$ temperature. Supernatant was separated and taken out.

2. As much as $350 \mu \mathrm{L}$ RLT buffer was added to supernatant and vortexed for 10 seconds.

3. Lysis buffer was added to the suspension and centrifuged at maximum speed for 5 minutes.

4. The suspension was centrifuged again for 10 minutes (at maximum speed) and transferred into a new tube.

5. Alcohol $70 \%$ was then added to the supernatant (with equal volume) and mixed evenly (without centrifuging).

6. $700 \mu \mathrm{L}$ of lysate yielded was then transferred to a $2 \mathrm{~mL}$ collection tube and vortexed at $\geq$ $10,000 \mathrm{rpm}$ for 15 seconds. The flow-through was discarded.

7. $500 \mu \mathrm{L}$ of RPE buffer was added to the spin-column and centrifuged at $>10.000 \mathrm{rpm}$ for 2 minutes.

8. Flow-through was discarded and the spin-column was transferred in a new collection tube.

9. $30-50 \mu \mathrm{L}$ of DEPC-water was added spin-column membrane filter and centrifuged at $>10.000$ for 1 minute. 
10. The collection tube containing the extracted RNA could be stored in the freezer at $-80^{\circ} \mathrm{C}$ temperature for later use.

11. Quality and quantity of the RNA samples could be assessed using electrophoresis method and absorbance measurement that were also performed at the later steps of the training.

Based on our observation, all the staffers were skilful enough in pipetting the solution with a certain volume unit. Minimum amount of bubbles was also created. This was crucial as it could interfere with the quantification process afterwards especially during PCR analysis (Lorenz, 2012). However, the staffers seemed to require more time to be able to understand fully about how to set-up the volume scales on the micropipette.

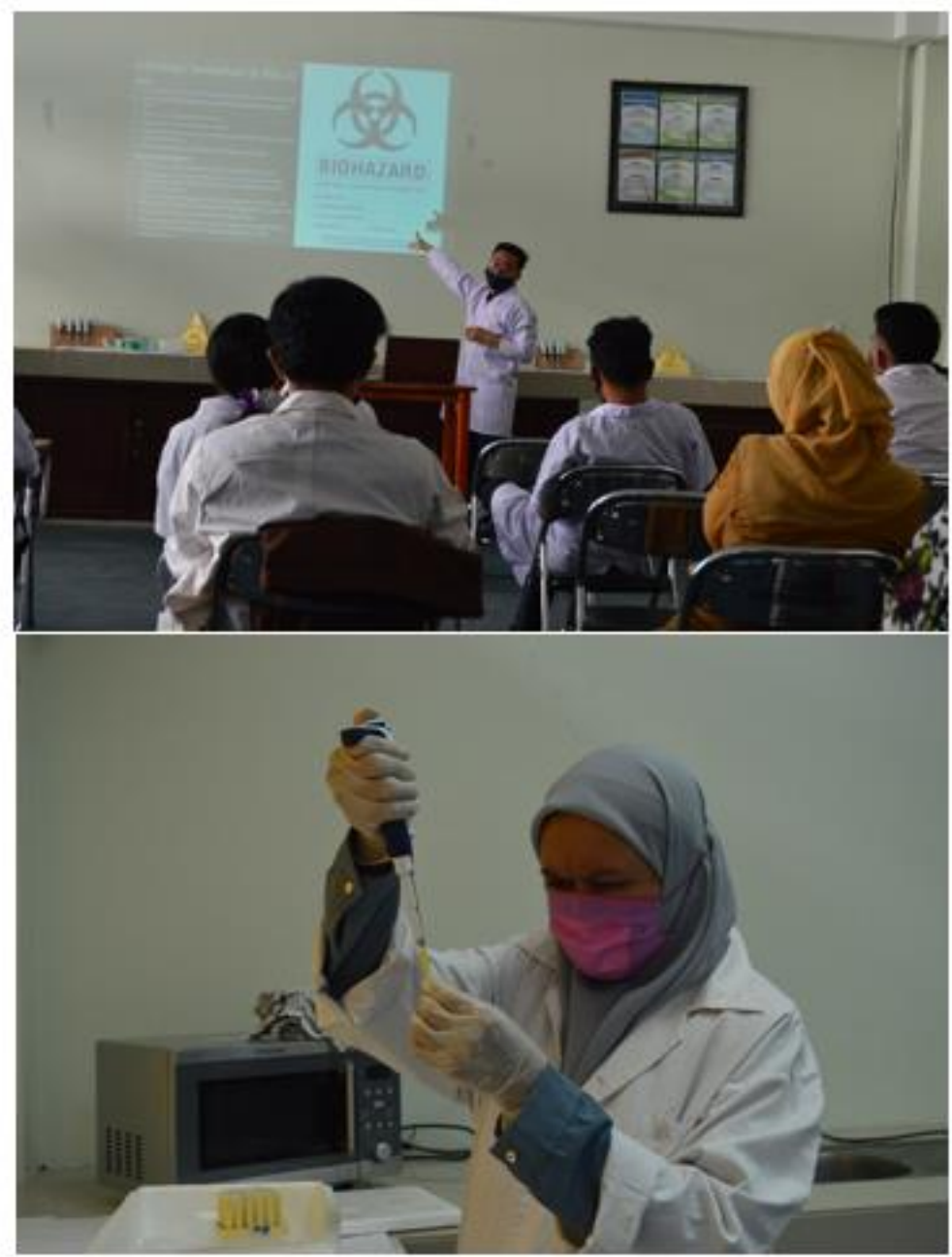

Figure 1. Theoretical and practical training of RNA extraction 
Another equipment involved in this stage was Centrifuge. The staffers didn't have any trouble in operating it but need to be informed on how to adjust the duration of spin with the purpose of the sample being centrifuged. For separating a solid matter from its solvent, higher rotational speed and longer duration would be needed. On the other hand, for mixing a solution evenly and to pull down any solution attached at the tube wall, then a lower rotational speed and shorter duration would be applied. After this stage, the RNA segment was stored at $-20^{\circ} \mathrm{C}$ for further use in Polymerase Chain Reaction (PCR), Electrophoresis and Quantitative Polymerase Chain Reaction (qPCR).

\section{Polymerase Chain Reaction (PCR)}

The bacterial RNA segment extracted was further used in the next day topic, Polymerase Chain Reaction. During this session, the samples were amplified by standard PCR machine using primers provided from the manufacturer. The staffers were taught on how to set up the PCR profile and run the PCR machines. Before genetic amplifying, they should prepare the chemical solution with the correct amount of volume and concentration as included in the manual. Similar with the previous stage, a mastery of micropipetting skills and centrifuge operating procedures were also essential for this stage to succeed. In addition, this session was preceded with a brief theoretical presentation on how the PCR machine works. Basically, this apparatus will make copies of our genetic materials (particularly DNA) that could be used for further purposes such as DNA sequencing, transfection and DNA cloning. The process comprised of 5 steps: 1) cDNA synthesis, where the RNA segment was converted into complementary DNA (cDNA); 2) initial denaturation at $95^{\circ} \mathrm{C}$ for 1 minute; 3) 45 repeated cycles: denaturation $\left(95^{\circ} \mathrm{C}, 30\right.$ seconds), annealing $\left(55^{\circ} \mathrm{C}, 30\right.$ seconds $)$ and extension $\left(72^{\circ} \mathrm{C}, 1\right.$ minute $\left.) ; 4\right)$ final extension at $72^{\circ} \mathrm{C}$ for 2 minutes and followed by 5) final hold at $25^{\circ} \mathrm{C}$ (Novel Coronavirus(2019-NCoV) Nucleic Acid Diagnostic Kit (PCR-Fluorescence Probing) SANSURE | Advanced Molecule Diagnosis Solutions, n.d.). 


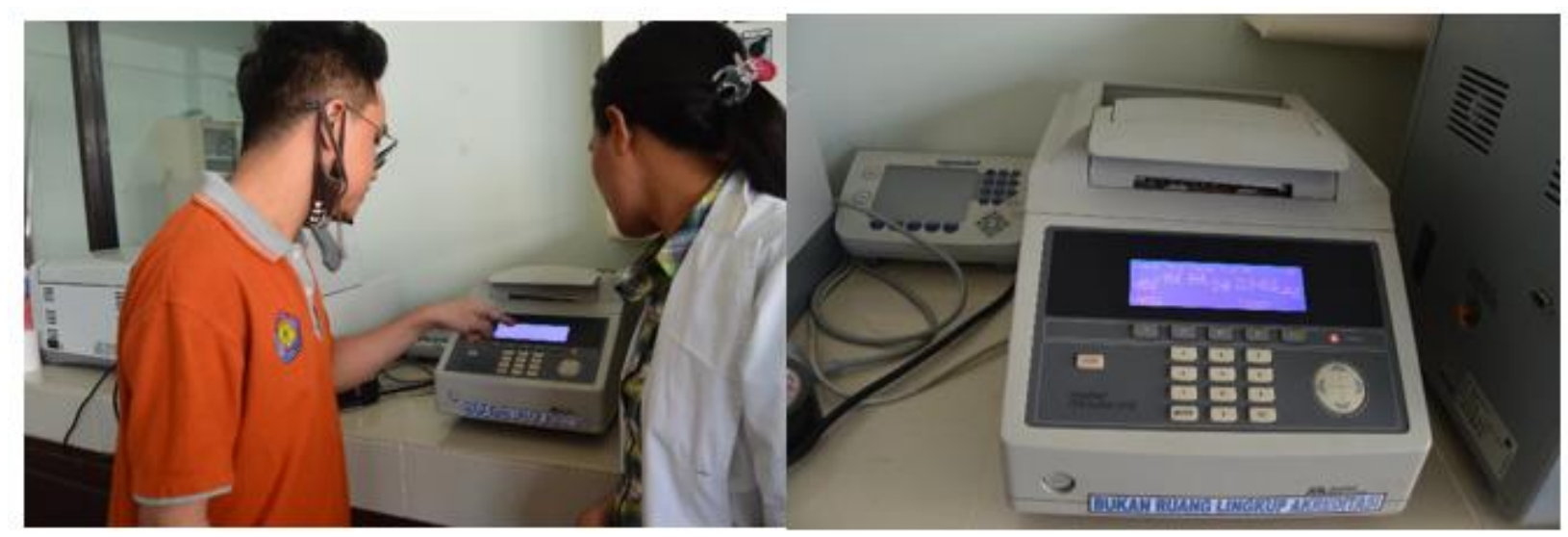

Figure 2. PCR profile set-up and operation

Other components needed also to be taken into consideration during this important step were: reverse transcriptase enzyme to make a DNA copy using RNA templates, specific primers (of both forward and reverse primers) that could annealed at the targeted gene(s), DNA polymerase that would catalyzed the extension of polynucleotides, and last but not least, the extracted RNA template obtained from Lactobacillus sp. After amplification, the amplified DNA was stored at $--20^{\circ} \mathrm{C}$ for further use the next day.

\section{Electrophoresis}

After conducting the PCR running, the amplified DNA (amplicon) was visualized using electrophoresis method. But before that, the amplicons were assessed its quality using an apparatus called Nano-photometer. This was also another example of a tool seldom been used in the laboratory as a result of a very minimum understanding on how to employ it. Basically, the Nano-photometer apparatus is similar to UV-Spectrophotometer in detecting the concentration of a certain material or sample. However, the Nano-photometer could notice even a much smaller amount of concentration that it only needed as much as $2 \mu \mathrm{L}$ of volume unit in order for it to quantify the sample. Also included in the machine was the ratio of A260/A280 which was important for determining the purity of genetic materials and also protein detected. A ratio of $\sim 2.00$ is considered a high quality genetic materials extracted (Interpretation of Nucleic Acid 260/280 Ratios, n.d.). 


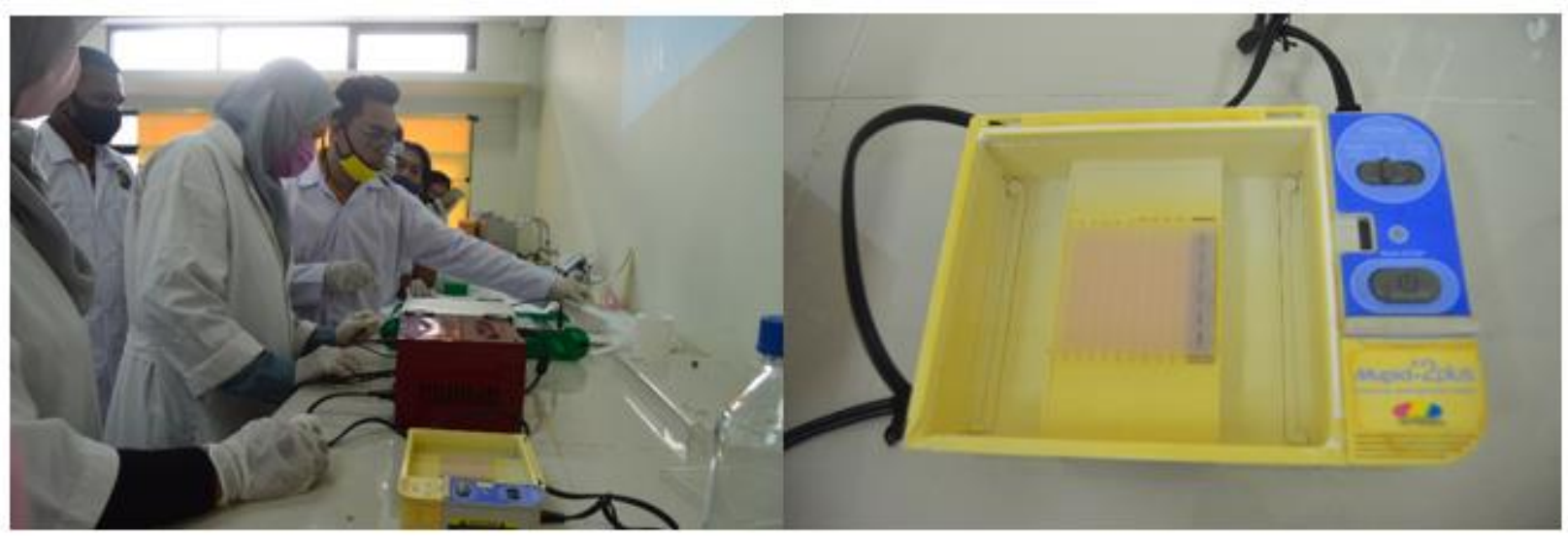

Figure 3. Electrophoresis lab practise

Based on the analysis, most of the RNA segments were not that qualified as it was below the value of 2.00. In retrospective, this might be due to the buffer solutions where the ones we used were actually more suitable for extracting viral RNAs (especially SARS-CoV-2). The bacteria themselves might have not been grown well enough to produce sufficient amount of RNA that could be extracted. Nonetheless, the RNA segments were still used for running the electrophoresis where the skill to be able to load the sample into the electrophoresis wells were highlighted more. The staffers were also involved in the process of making the agarose gel $(2.5 \%$ and 3\%), TBE buffer and setting up the electrophoresis apparatus. The apparatus was run for approximately one hour and a half. In each gel, the participants loaded both of their amplified RNA and extracted RNA (without amplification through PCR) in different wells. Extra agarose gels were also provided for the staffers for practising their skills in loading the wells using only loading dye (without any RNA samples). 


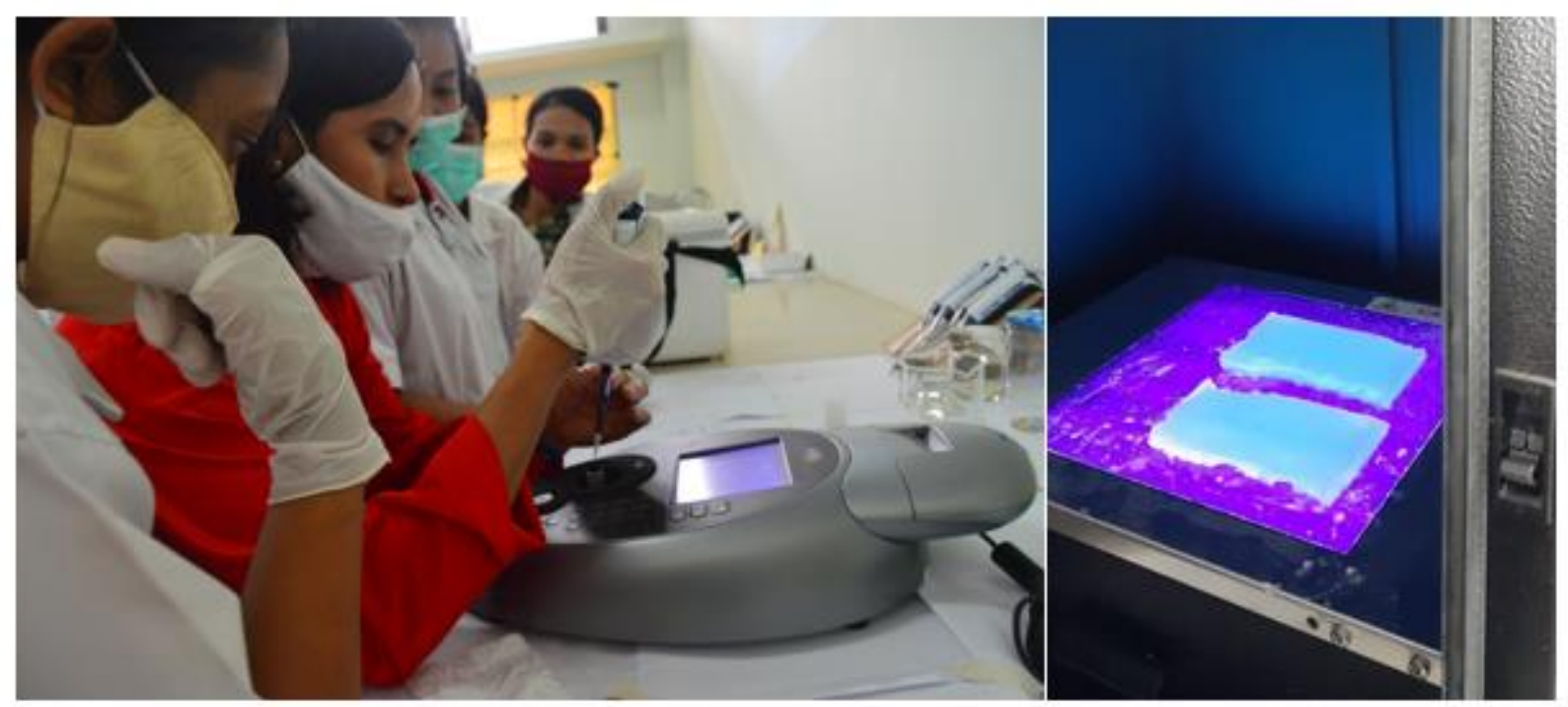

Figure 4. Nano-spectrophotometer (left) and UV-gel doc (right) operation

After separating the samples, the agarose gels were observed under UV-light in a Gel Doc. It was also the first time the staffers got to know how to operate the Gel Doc and the purpose of it. During observation, unfortunately, no bands were produced. This might be caused by not enough RNA were extracted and amplified. The primers used was also the ones specifically designed for SARS-CoV-2 that would not indeed annealed with the targeted genes in the bacterial cDNA of Lactobacillus sp. In spite of it, the trainers stressed that the method and/or procedures were more imperative during the training while the ideal results were at least shown through power point slides that could compensate with the actual results. In addition, on how to estimate the molecular size of a certain gene (shown as band) based on a ladder used was also thought theoretically during this session.

\section{Quantitative Polymerase Chain Reaction (qPCR)}

The aliquoted RNA samples were also spared for qPCR analysis at the very last day of the training. The profile set up for qPCR was the same as used for standard PCR. The staffers were comprehended on the basic principles that differ between standard PCR and qPCR, but most importantly, they were taught on how to operate the qPCR machine, setting up its profile and further analysis of the data results. 


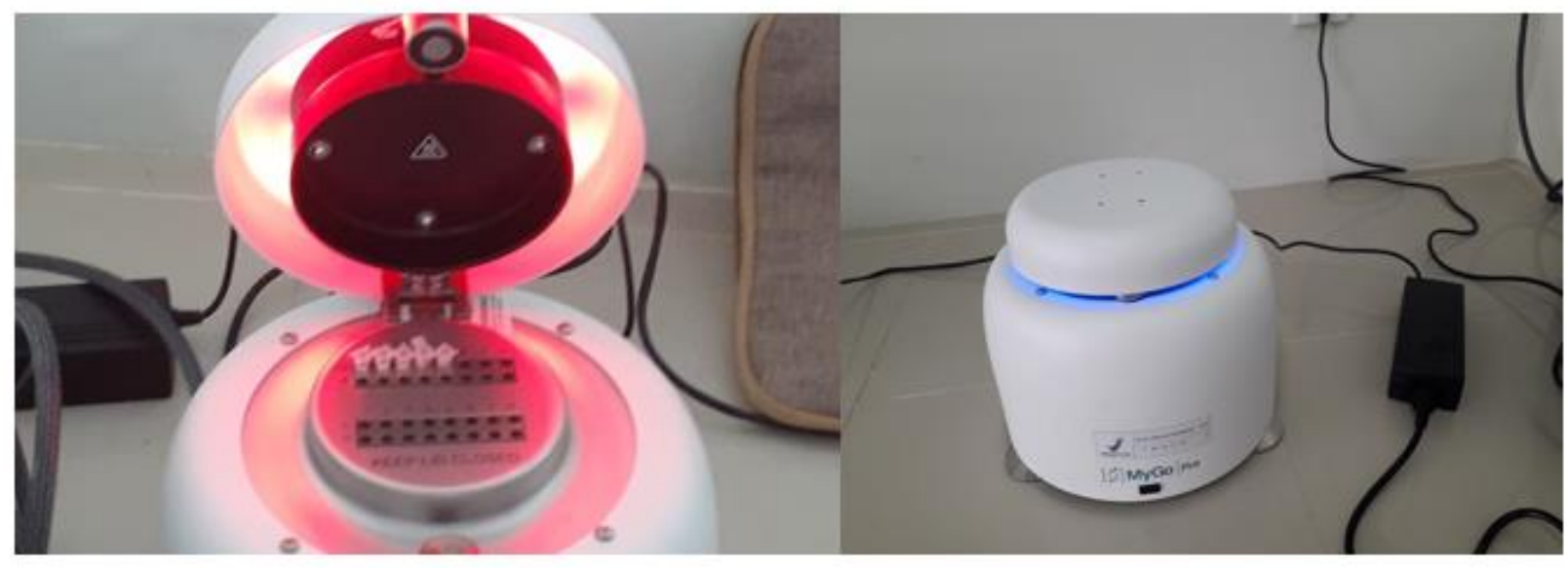

Figure 5. qPCR operation

At first, the staffers prepared a serial dilution to have a look at the standard curve. The standard curve would be useful in calculating the efficiency of the qPCR reaction (The Obligate QPCR Standard Curve - Bitesize Bio, n.d.). This served as an indicator of good-skilled technique during reagent and solution preparation especially the consistency of pipetting. Based from the qPCR results, the staffers still needed to put consistency which includes the aspects of volume, concentration and pipetting technique. The next step was to run the samples. In addition, sample containing segments of SARS-CoV-2 was also used as a positive control. The main goal during this step of training was to give a sufficient comprehension in determining positive samples and differ it with the negative ones based on the Cycle Threshold (CT). The presumed negative samples used came from the ones that were previously extracted and amplified but however, did not show any bands during electrophoresis. This was plausible as it was extracted from bacterial sample that would not have matched the viral primers during amplification.

Based on observations, the staffers eventually did understand how to set up the PCR profile, run it, and interpret its results. However, pipetting techniques still need to be improved in order to obtain a higher qPCR reaction efficiency.

\section{Training Relevancy to the Field of Agriculture}

Proficiency in performing and operating those equipment and methods would further expand Politani Kupang's activities related to Agricultural researches and lab practices. 
Agricultural application of Biomolecular technologies could be integrated for instance in helping a more effective and efficient collection, classification and conservation of qualified seed. This serves as an improvement to conventional method which is mostly based on phenotypic trait that could usually causes confusions because of over-lapping characteristics. By using molecular markers, we could ensure whether desired offspring have been produced or not based on a targeted genes identification. Probing gene expression could also better represent a plant's response to different kinds of fertilizer and concentration or a livestock animal's response to a wide range of probiotic, prebiotic and/or hormones. Not to mention, transgenic plants which employed DNA manipulation method for quality improvement (Fang et al., 2016). In the field of Animal Husbandry and Veterinary Sciences, biomolecular-based approaches could be integrated in diagnostic test with high specificity and sensitivity of a certain pathogenic microorganism infecting (Borroto, 2008). All examples mentioned above would definitely implement those basic Biomolecular-related methods that have been discussed earlier as the initial step.

\section{CONCLUSION AND RECOMMENDATION}

Several things can be deduced based on the biomolecular enhancement training program above, which are:

1. Based on Nano-spectrophotometer analysis, the staffers didn't obtain a highly purified RNA sample, however, the reason behind it was that the method used was actually suited for viral extraction and therefore would not optimally isolate bacterial RNA (Lactobacillus sp.) used during the training. Nevertheless, the staffers still could manage to practise the standard procedure of RNA extraction including operating apparatuses involved during this process such as: micropipette, microcentrifuge, quick spin, Nano-spectrophotometer, most of which have never been known and used before.

2. During Polymerase Chain Reaction (PCR) session, despite the fact that the staffers didn't understand completely on the theoretical aspect of the apparatus (which is not required for their profession), they still could operate the PCR machine including setting up the PCR profile, as well as creating and renaming sample group at the screen. 
1. For electrophoresis method, now the staffers have already known how to set the apparatus, prepared the buffer solution, measured the bands and observed it under the UV gel doc.

2. For qPCR method, the staffers were able to set up the qPCR profile both for singleplex and multiplex analysis, run the machine and interpret the result based on Cycle Threshold (CT) that has been determined before or based on the standard protocol given.

However, for a more enhanced and competent skills displayed by the laboratory staffers in the field of Biomolecular, several things could be considered:

1. Follow-up trainings should be conducted regularly either in Politani Kupang or by sending the staffers to any adequate laboratories that could provide biomolecular-related trainings.

2. The teaching staffs (lecturers) equipped with biomolecular skills should integrate this field more on their subject curriculum where possible that in one way could also benefit the lab staffers by being more familiar with the method(s) as they are the ones that would assist in lab practises or analysis inside the lab.

3. Whenever the institution plans for any facility procurement especially associated with Biomolecular aspect, it would be better if coupled with enhancement training in order for the staffers to be able to operate the apparatuses and accommodate with its data analysis.

\section{ACKNOWLEDGEMENT}

This training program would be impossible to conduct without the permission and support of the higher and the highest level of Politani Kupang bureaucracy, Forum Academia NTT (FAN), the Institute of Resource Governance and Social Change (IRGSC) Kupang, and also the Head of the Laboratories of Politani Kupang. Therefore, we would like to convey our endless gratitude as well as looking forward for any next training(s) to come. For the participants, your tenacity and curiosity were very well observed, acknowledged, and highly appreciated. It showed how much dedication you are willing to contribute for the quality of your institution, Agricultural Polytechnic of Kupang. 


\section{REFERENCES}

Bangham, T. (2018, September 25). What is vocational education? [Text]. European Vocational Skills Week - Commission. https://ec.europa.eu/social/vocational-skills-week/what-vocationaleducation_en

Borroto, C. G. (2008). Biotechnology and Its Application to Veterinary Science. Conf. OIE, 231240. https://webcache.googleusercontent.com/search?q=cache:SCvlPBiXKS0J:https:// www.oie.int/doc/ged/ D6070.PDF+\&cd=6\&hl=en\&ct=clnk\&gl=id\&client=firefox-b-d

Education, I. (2013, July 22). Vocational Training vs University Education. Inspire Education | Online Courses \& Accredited Training Australia. https://www.inspireeducation.net.au/blog/ vocational-training-vs-university-education/

Fang, J., Zhu, X., Wang, C., \& Shangguan, L. (2016). Applications of DNA Technologies in Agriculture. Current Genomics, 17(4), 379-386. https://doi.org/10.2174/ 1389202917666160331203224

Importance of vocational education | Independent. (n.d.). Retrieved August 1, 2020, from http://m.theindependentbd.com/home/printnews/220620

Interpretation of Nucleic Acid 260/280 Ratios. (n.d.). Retrieved August 1, 2020, from http://webcache.googleusercontent.com/search?q=cache:xDVhhaetzOAJ:tools.thermofisher.com/ content/sfs/brochures/T123-NanoDrop-Lite-Interpretation-of-Nucleic-Acid-260-280-

Ratios.pdf $+\& c d=2 \& h l=e n \& c t=c l n k \& g l=i d \& c l i e n t=$ firefox $-b-d$

Lorenz, T. C. (2012). Polymerase Chain Reaction: Basic Protocol Plus Troubleshooting and Optimization Strategies. Journal of Visualized Experiments: JoVE, 63. https://doi.org/10.3791/3998 
Novel Coronavirus(2019-nCoV) Nucleic Acid Diagnostic Kit(PCR-Fluorescence Probing) SANSURE | Advanced Molecule Diagnosis Solutions. (n.d.). Retrieved August 1, 2020, from http://eng.sansure.com.cn/index.php?g=\&m=article \&a=index $\& \mathrm{id}=81$

The Obligate qPCR Standard Curve-Bitesize Bio. (n.d.). Retrieved August 1, 2020, from https://webcache.googleusercontent.com/search?q=cache:i9VQYpXmuUEJ:https://bitesizebio.co $\mathrm{m} / 31470 /$ obligate-qpcr-standard-curve/ $+\& \mathrm{~cd}=2 \& \mathrm{hl}=\mathrm{en} \& \mathrm{ct}=\mathrm{clnk} \& \mathrm{gl}=\mathrm{id} \& \mathrm{client}=$ firefox-b-d 